\title{
Modulating semantic feedback in visual word recognition
}

\author{
MARILYN CHAPNIK SMITH \\ University of Toronto, Scarborough, Ontario, Canada \\ and \\ DEREK BESNER \\ University of Waterloo, Waterloo, Ontario, Canada
}

\begin{abstract}
According to the interactive activation framework proposed by McClelland and Rumelhart (1981), activation spreads both forward and backward between some levels of representation during visual word recognition. An important boundary condition, however, is that the spread of activation from lower to higher levels can be prevented (e.g., explicit letter processing during prime processing eliminates the well-documented semantic priming effect). Can the spread of activation from higher to lower levels also be prevented? This question was addressed with a choice task procedure in which subjects read a prime word and then responded to a target, performing either lexical decision or letter search depending on the color of the target. A semantic context effect was observed in lexical decision, providing evidence of semantic-level activation. In contrast, there was no semantic context effect in the letter search task, despite evidence of lexical involvement: Words were searched faster than nonwords. Further evidence of lexical involvement in the letter search task appeared in Experiment 2 in the form of greater identity priming for words than for nonwords. The results of these experiments are consistent with the conclusion that feedback from the semantic level to the lexical level can be blocked. Hence, between-level activation blocks can be instantiated in both bottom-up and top-down directions.
\end{abstract}

One of the most influential frameworks for language processing over the last several decades has been the interactive activation (IA) framework (e.g., McClelland, 1987; McClelland \& Rumelhart, 1981; see also Morton 1969 , but note that this model assumes thresholding between lexical and semantic levels on the feed-forward cycle). The central assumptions of this framework for visual word recognition are that (1) there are a number of distinct levels, and (2) they are interactively engaged. In Morton's framework, much of the emphasis has been on the word (logogen) and semantic levels (i.e., "the nature of the relationship between the Logogen System and the Context System is such that there is continuous exchange of information between the two"; Morton, 1969, p. 166). Word and semantic levels are also represented in the McClelland and Rumelhart framework, but considerably more emphasis has been placed on interactive activation between word and letter levels (as in the study of the word superiority effect).

This work was supported by research grants from the Natural Sciences and Engineering Research Council of Canada to M.C.S. (OGPIN012) and D.B. (A0998). We thank Dave Balota, Ken Paap, and Ken Forster for provocative reviews. Correspondence should be addressed to M. C. Smith, Life Sciences Division, University of Toronto, Scarborough, ON, M1C 1A4 Canada (e-mail: smith@ scar.utoronto.ca), or D. Besner, Psychology Department, University of Waterloo, Waterloo, ON, N2L 3G1 Canada (e-mail: dbesner@watarts.uwaterloo.ca).
Given the prominence of the IA framework, it is a curious fact that the much investigated phenomenon of semantic context - the facilitated processing of a target word when it is preceded by a related word as opposed to an unrelated word (see, e.g., Neely's [1991] review) -is rarely discussed in terms of the between-level spread-ofactivation assumption inherent in this framework. ${ }^{1}$ Instead, the most widely favored explanations of semantic context assume that it is restricted to the semantic level. These explanations are cast in terms either of (1) spreading activation between related entities within a level, as in a number of localist accounts (e.g., Collins \& Loftus, 1975; Neely, 1991), or (2) overlap in terms of semantic microfeatures within a level, as in several parallel distributed processing accounts (e.g., Masson, 1991, 1999; McRae \& Boisvert, 1998).

Contrary to the prevalent view that semantic context is restricted to the semantic level, there are several phenomena that are consistent with a multiple-locus account in which activation at the semantic level feeds down to the lexical level following prime processing. First, in both lexical decision and naming, targets that are degraded yield a larger priming effect than targets that are presented more clearly (e.g., Becker \& Killion, 1977; Besner \& Smith, 1992; Borowsky \& Besner, 1993; Meyer, Schvaneveldt, \& Ruddy, 1975; Stolz \& Neely, 1995). Second, word frequency and stimulus quality have additive effects on reaction time (RT) in both lexical decision and naming (Balota \& Abrams, 1995; Becker \& Killion, 
1977; Borowsky \& Besner, 1993; Herdman, Chernecki, $\&$ Norris, 1999; Plourde \& Besner, 1997). Third, semantic context effects are larger for low- than for highfrequency word targets in lexical decision (Becker, 1979; Borowsky \& Besner, 1993). Given additive factors logic (Sternberg, 1969, 1998), the pattern observed across all these experiments is difficult to reconcile with the idea that semantic context affects only one stage of processing. Instead, the pattern of factor effects on RT is consistent with a two-stage model in which degradation affects an early stage, word frequency affects a subsequent stage, and semantic context affects both stages (Besner \& Smith, 1992; Borowsky \& Besner, 1993). In terms of a multiple-levels framework, this pattern is consistent with the hypothesis that the prime activates semantics, which in turn feeds activation down to the lexical level before the target is presented (note that lexical-level "priming" must involve activation via semantics because in neither the Morton nor in the McClelland and Rumelhart IA framework are there links between nodes at the lexical level that allow activation).

\section{Activation Blocking}

A recent study by Stolz and Neely (1995) provides converging evidence that semantic context effects involve multiple levels, and is also consistent with the conclusion that it is possible to block semantic-level activation from feeding down to the lexical-level in lexical decision. Stolz and Neely found that whereas semantic context interacted with degradation when the proportion of related prime-target trials (RP) was .5 (suggesting that both factors were affecting an early processing stage), these same two factors had additive effects on RT when $\mathrm{RP}$ was lowered from .5 to .25 (suggesting that semantic context did not affect early target processing when RP was low). Hence, it appears that feedback from semantics to the lexical level occurs only when RP is high.

The present investigation further explores the issue of whether semantic-level processing can be prevented from feeding back to the lexical level in both lexical decision and letter search tasks despite a high level of RP (.5). There is already considerable evidence for the modulation of semantic activation when subjects are required to engage in explicit letter-level processing during prime presentation. The normally robust semantic context effect is typically not significant when subjects engage in a letter-level task before making a lexical decision or naming a target (e.g., Chiappe, Smith, \& Besner, 1996; Friedrich, Henik, \& Tzelgov, 1991; Henik, Friedrich, Tzelgov, \& Tramer, 1994; Smith, Theodor, \& Franklin, 1983; Stolz \& Besner, 1996). One account of this finding is that performing letter search on the prime blocks the spread of activation from the lexical level to the semantic level. ${ }^{2}$

Letter search on the prime does not, however, prevent word-level activation. For example, Stolz and Besner (1998) reported that despite the standard absence of a se- mantic context effect, primes like MARKED facilitated the processing of a target like MARK relative to a prime like MARKET, even though these two different primes share the same degree of orthographic and phonological overlap with the target. Relatedly, in a study of picture processing, Smith, Meiran, and Besner (2000) found that living/nonliving decisions to a picture target such as "chair" were facilitated following letter search of the prime word CHAIR but not following letter search of the semantically related prime word TABLE. These data were interpreted as providing evidence of a direct link between the lexical-level representation of the prime word and the pictogen level of representation for a picture, independent of the semantic system. In terms of the activation block hypothesis, both of these experiments suggest that the block must occur after the lexical level (to account for morphemic- and object-level priming), but before the semantic level (to account for the absence of a semantic context effect).

Further evidence that letter search per se does not prevent lexical activation is provided by three observations. First, letter search is faster through words than through orthographically matched nonwords (Besner, Smith, \& MacLeod, 1990; Krueger \& Weiss, 1976). Second, responding "no" in the letter search task is slowed when the string is a pseudohomophone like BRANE, and the (nonpresented) real word BRAIN contains the target letter (Ziegler, Van Orden, \& Jacobs, 1997, Experiment 4). Finally, target-"present" judgments are more accurate in a letter search task when both the presented pseudohomophone and its nonpresented real-word counterpart contain the target letter as compared with a nonword that is not a pseudohomophone (Ziegler et al., 1997, Experiment 2). Some or all of these effects could result from feedback from the lexical level to the letter level, as in the McClelland and Rumelhart framework, or, no feedback from lexical to letter level, but lexical level information combining with letter information at a decision stage (Paap, Newsome, McDonald, \& Schvaneveldt, 1982). For present purposes the important point is that letter search does not prevent lexical activation.

Given that activation in the IA framework is assumed to feed both forward and backward, the question addressed here concerns whether activation blocks occur only on the feed-forward cycle or whether they can also be deployed on the feedback cycle. For example, when target processing (rather than prime processing) requires explicit letter-level processing, does the presentation of a prime that is semantically related to the target help, hinder, or have no effect on target processing? One could imagine that proofreading, from the perspective of detecting spelling errors, would be hindered by semantic activation to the extent that it encourages conceptual-level processing at the expense of letter-level processing. More locally, semantic activation would also activate other words in addition to the target word, and this might lead to increased activation of irrelevant letters, making it 
more difficult to detect a target letter. From this perspective, an activation block might make performance on the letter search task more efficient.

The existing data do not yield an unambiguous answer to the question of whether an activation block can be deployed on the feedback part of the cycle (i.e., between semantic and lexical levels). Blum and Johnson (1993) reported a series of five experiments in which prime words failed to facilitate letter search through a subsequently presented target that was semantically related to the prime. On the face of it, such data are consistent with the deployment of an activation block that prevents activation at the semantic level from feeding down to lower levels. However, an alternative account is that constituents of the target task induce an activation block in which the prime is blocked from activating semantics, despite the fact that there is no explicit letter processing demanded of the prime (see, e.g., Buchanan \& Besner, 1993, for such an argument).

By way of summary, then, it is unclear how to interpret Blum and Johnson's (1993) results. Either semantics are activated, but prevented from feeding down to the lexical level, or semantics are not activated in the first place, as seen in certain prime processing tasks (e.g., Chiappe et al., 1996; Friedrich et al., 1991; Smith et al., 2000; Smith et al., 1983; Stolz \& Besner, 1996, 1998). The present experiment addresses this issue with the use of a choice task procedure. Here, prime presentation is followed by a colored target. The color of the target specifies the target task, with one color cuing lexical decision and another cuing letter search (for the presence or absence of a repeated letter). If semantics are activated by the prime, but the spread of activation to lower levels is blocked, then the effects of semantic relatedness will differ for letter search and for lexical decision. Because lexical decision can be accomplished by monitoring the semantic level, it should be facilitated when the prime consists of a related word (e.g., Borowsky \& Besner, 1993; Stolz \& Neely, 1995). In contrast, since feedback to lower levels is blocked, there should be no evidence of semantic priming in letter search. On the other hand, if the presence of letter search as a target task on some of the trials instantiates an experiment-wide set in which semantics are prevented from being activated by the prime, then a semantic context effect should not be observed in either task.

\section{EXPERIMENT 1}

\section{Method}

Participants. A total of 120 subjects participated in this experiment. Subjects were University of Waterloo undergraduates who were paid for their participation.

Stimuli. Two hundred associatively related word pairs culled from a variety of semantic priming experiments were prepared (the stimulus set is available from the authors) so that half the target words contained no repeated letters (e.g., FATHER) and half contained one repeated letter (e.g., DOCTOR). Nonrelated word pairs were formed by randomly rearranging primes and targets of the related pairs. In addition, 100 word-nonword pairs were created, with half the nonword targets containing no repeated letters (e.g., BLACE) and half containing one repeated letter (e.g., PEKCE). The 100 pronounceable nonwords were formed by changing a single letter of a real word.

The prime word was always white, whereas the target word appeared in either blue or red. For half the subjects, blue indicated lexical decision (is the target a word?) and red indicated letter search (does the target contain a repeated letter?). For the other half of the subjects, this color/task assignment was reversed. Subjects responded yes or no by pressing the indicated keys on the keyboard. A message across the top of the screen reminded subjects which response they were to make to each color.

Procedure. An IBM-clone computer and CRT were used for the presentation of stimuli and recording of responses. Stimuli were horizontally centered on the screen at a vertical distance of $10.7 \mathrm{~cm}$ from the top of the screen. Following a 400-msec fixation point (an asterisk), the prime was presented for $200 \mathrm{msec}$. The target appeared $192 \mathrm{msec}$ after prime offset (resulting in stimulus onset asynchrony [SOA] of $392 \mathrm{msec}$ ) and terminated when a response was made. The intertrial interval was $1 \mathrm{sec}$.

A total of 300 stimulus pairs were presented to each subject: 100 related word pairs, 100 unrelated word pairs, and 100 word-nonword pairs. Assignment of targets (both words and nonwords) was counterbalanced across subjects so that each target appeared equally often in the two tasks. Each target word appeared in a related pair for half the subjects and in an unrelated pair for the others. Half the targets contained a repeated letter. Half the targets were red and half were blue, so that subjects performed lexical decision on 150 trials and letter search on 150 trials. In lexical decision there were 50 word targets preceded by a related word prime, 50 word targets preceded by an unrelated word prime, and 50 nonword targets preceded by a word. Hence, the response probabilities (yes/no) were 2:1 (i.e., subjects made yes responses to 100 word targets, and no responses to 50 nonword targets). In the letter search task, subjects were presented with 100 word targets, half preceded by a related word prime and half by an unrelated word prime, and 50 nonword targets preceded by a word prime. Here the response probabilities (yes/no) were 1:1, because half the targets contained a common letter and half did not. Each subject received a different random ordering of stimuli.

Practice consisted of two blocks of 48 trials. After each block, subjects were informed of their accuracy. If they attained an accuracy level of $90 \%$, they went on to begin the test trials. If not, they were given a third block of 48 practice trials before beginning the test trials.

\section{Results}

The data are presented in Table $1 .{ }^{3}$ Mean RT was calculated via a recursive trimming procedure that limited responses to those within a range of $2.5 S D$ above or below the mean, resulting in a loss of $5 \%$ of the data. Because the effect of response type (yes/no) did not enter into any interactions with semantic relatedness in letter search,

Table 1

Semantic Priming: Mean Target Reaction Time (RTs, in Milliseconds) and Percentage Error (PE) in the Choice Task Procedure of Experiment 1

\begin{tabular}{|c|c|c|c|c|}
\hline \multirow{3}{*}{$\begin{array}{c}\text { Prime-Target } \\
\text { Relationship }\end{array}$} & \multicolumn{4}{|c|}{ Task } \\
\hline & \multicolumn{2}{|c|}{$\begin{array}{c}\text { Lexical } \\
\text { Decision }\end{array}$} & \multicolumn{2}{|c|}{$\begin{array}{l}\text { Letter } \\
\text { Search } \\
\end{array}$} \\
\hline & RT & $\mathrm{PE}$ & RT & $\mathrm{PE}$ \\
\hline Unrelated word & 875 & 2.7 & 1,285 & 7.0 \\
\hline Related word & 845 & 2.4 & 1,300 & 7.0 \\
\hline Difference $(\mathrm{U}-\mathrm{R})$ & 30 & 0.3 & -15 & 0 \\
\hline
\end{tabular}


the data are collapsed across this factor and not considered further.

An initial overall analysis of variance (ANOVA) of the word target data yielded a main effect of task, with subjects responding more slowly $\left[F(1,118)=453.98, M S_{\mathrm{e}}=\right.$ $106,500, p<.001]$ and making more errors $[F(1,118)=$ $\left.90.9, M S_{\mathrm{e}}=44.74, p<.001\right]$ in letter search than in lexical decision. Although the main effect of semantic relatedness was not significant, the interaction of task $X$ semantic relatedness was significant for RT $[F(1,118)=$ $\left.5.52, M S_{\mathrm{e}}=15,478, p<.02\right]$, but not for errors $[F(1,118)$ $\left.=2.1, M S_{\mathrm{e}}=15.6, p<.15\right]$. Separate ANOVAs for each task confirmed the presence of a semantic context effect in lexical decision for RT $\left[F(1,118)=9.4, M S_{\mathrm{e}}=9,616\right.$, $p<.005]$ and marginally for errors $[F(1,118)=3.3$, $\left.M S_{\mathrm{e}}=9.2, p<.07\right]$. In contrast, there was no semantic context effect in letter search $(F<1$ for both RT and errors $){ }^{4}$

Finally, an analysis of the letter search data indicated that search through words $(1,285 \mathrm{msec}, 7.0 \%$ errors $)$ was faster than through nonwords $(1,361 \mathrm{msec}, 8.2 \%$ errors $)$ $\left[F(1,118)=32.5, M S_{\mathrm{e}}=22,317, p<.001\right]$.

\section{Discussion}

The first observation is that performance under these choice task conditions is quite slow relative to when the task is held constant throughout a block. This slow performance is standard when the target stimulus affords responses to both tasks (e.g., Allport, Styles, \& Hsieh, 1994).

The other results of Experiment 1 are also straightforward. A semantic context effect was observed in lexical decision, replicating the standard finding (see, e.g., Neely's [1991] review). In contrast, semantic context did not affect performance in the letter search task despite evidence of lexical involvement in the form of words being processed more quickly than nonwords. Thus, there is no evidence that the influence of semantic relatedness extends down beyond the semantic level in the present context. Given the IA framework, our preferred interpretation is that feedback from the semantic level to the lexical level can be blocked when letter search is performed on the target.

In other accounts of visual word recognition, however, there is no feedback between lexical and letter levels (e.g., Johnston, 1981; Paap et al., 1982). If letter search is not open to lexical influence through feedback, then the failure to observe semantic priming in letter search could be considered unsurprising, and cannot be used in support of the claim that there is an activation block. On the other hand, letter search through words is faster than through nonwords in this experiment, suggesting lexical involvement in some form (see also Besner et al., 1990; Krueger \& Weiss, 1976; Ziegler et al., 1997). We thus assume that (1) semantic activation is blocked from feeding down to the lexical level, and (2) the lexical level contributes to performance in the letter search task in some way (i.e., either through feedback to the letter level following bottom up processing or through a contribution to the decision level, as in Paap et al.'s, 1982, model).
Nonethless, it could be argued that since no attempt was made in Experiment 1 to control for orthographic/ phonological differences between words and nonwords, faster search through words may result entirely from orthographic/phonological factors at the letter and/or phoneme level rather than to any influence from the lexical level. Indeed, some theorists and reviewers (e.g., Paap, personal communication, February 28, 1999) take the view that it is difficult, perhaps impossible, to match words and nonwords for all orthographic and phonological factors affecting the letter and phoneme levels. Furthermore, previous demonstrations to the contrary notwithstanding, it is preferable to provide evidence of lexical influence in the context of the choice task procedure developed here, especially given the claim that this procedure invites (unconscious) activation blocking. Experiment 2 therefore addresses this issue of lexical influence by determining whether there is greater identity priming of words than of nonwords in the letter search task. If only orthographic/phonologicalstructure at the letter/phoneme level is functional, then repetition should either benefit words and nonwords equally, or benefit nonwords more than words on the grounds that repetition makes poor structure relatively more easy to process than good structure (by analogy, repetition benefits low-frequency words more than high-frequency words in lexical decision; e.g., Scarborough, Cortese, \& Scarborough, 1977). In contrast, if lexical-level processes are operative and affected by repetition, then words should benefit more than nonwords on the grounds that, at least in localist representations, nonwords have no lexical-level representations.

The discussion has taken a few twists and turns; it is therefore useful to recapitulate the main line of argument. If lexical-level processes are operative in the letter search task in the context of the choice task procedure, then the absence of a semantic context effect in letter search combined with its presence in lexical decision is taken to imply that semantic processing is restricted to the semantic level, rather than feeding down to the lexical level. The rationale is that if semantic activation affected the lexical level, then the letter search task should have produced a semantic context effect given that the letter search task is argued to be affected by lexicallevel processing. The purpose of Experiment 2, therefore, is to buttress the claim that, in the context of the choice task procedure, the letter search task is affected by lexicallevel processing.

\section{EXPERIMENT 2}

\section{Method}

Participants. Thirty-five students from the University of Toronto participated in this Experiment in return for course credit.

Stimuli. A stimulus set was prepared consisting of 400 word pairs and 400 nonword pairs. Nonwords were formed by changing one letter of a real word to form a pronounceable nonword. Half the pairs were identical and half were unrelated, formed by randomly rearranging primes and targets from the identical pairs. Word-nonword and nonword-word pairs were also included (again with half the 
targets containing a repeated letter), in order to prevent the subject from using the prime to predict the nature of the target (e.g., if the task was lexical decision then knowing what the prime was would perfectly predict whether the target was a word or a nonword). A total of 400 stimulus pairs were presented to each subject, 200 with word targets and 200 with nonword targets. Of the 200 pairs containing a word target, there were 60 identical word pairs, 60 unrelated word pairs, and 80 nonword -word pairs. Of the 200 pairs containing a nonword target, there were 60 identical nonword pairs, 60 unrelated nonword pairs, and 80 word-nonword pairs. Hence, half the primes were words. Half of all targets contained a repeated letter. Half the targets were presented in one color and half in the other color.

Procedure. The same choice task procedure was employed as in Experiment 1. Prior to beginning the experiment, subjects had 80 practice trials, containing the same distribution of trials as in the experiment.

\section{Results}

As in Experiment 1, mean RT was calculated via a recursive trimming procedure that limited responses to those within a range of $2.5 S D$ above or below the mean.

Lexical decision. The lexical decision data can be seen in Table 2.5 There was a main effect of repetition for both RT $\left[F(1,34)=12.0, M S_{\mathrm{e}}=16,348, p<.001\right]$ and errors $\left[F(1,34)=262.0, M S_{\mathrm{e}}=.64, p<.001\right]$, a main effect of lexical status (words vs. nonwords) for both RT $\left[F(1,34)=89.0, M S_{\mathrm{e}}=20,419, p<.001\right]$ and errors $\left[F(1,34)=92.7, M S_{\mathrm{e}}=2.0, p<.001\right]$, and an interaction between these two factors, with a larger effect of repetition for words than for nonwords for both RT $\left[F(1,34)=15.9, M S_{\mathrm{e}}=23,727, p<.001\right]$ and errors $\left[F(1,34)=91.5, M S_{\mathrm{e}}=0.64, p<.001\right]$.

Letter search. An ANOVA on the RT data (restricted to the word-word and nonword-nonword pairs, the only conditions of interest) yielded main effects of repetition $\left[F(1,34)=52.2, M S_{\mathrm{e}}=85,339, p<.001\right]$ and lexical status $\left[F(1,34)=7.7, M S_{\mathrm{e}}=50,731, M S_{\mathrm{e}}=50,731, p<\right.$ .01]. More importantly, there was an interaction between these two factors, with more repetition priming for words than for nonwords $\left[F(1,34)=48.2, M S_{\mathrm{e}}=74,234, p<\right.$ $.001]$. There were no significant error effects.

\section{Discussion}

The results of this Experiment provide converging evidence for word-level involvement in the letter search task. First, replicating earlier findings (e.g., Besner et al., 1990; Krueger \& Weiss, 1976; Ziegler et al., 1997), letter search was faster through words than through nonwords.
More importantly, repetition priming provided larger benefits for words than for nonwords.

\section{GENERAL DISCUSSION}

A semantic context effect was observed in lexical decision but not in letter search in Experiment 1. There was also evidence of lexical involvement in the letter search task of Experiment 1 in the form of faster processing for words than nonwords. Experiment 2 provides converging evidence that the letter search task benefits from lexical-level processing in the form of a larger identity priming effect for words than for nonwords. Given the IA framework discussed in the introduction that guided this investigation, our preferred account of the absence of a semantic context effect in the letter search task is that semantic activation is prevented from feeding down to the lexical level in the context of the choice task procedure. We elaborate on this account below. That said, we would like to avoid leaving the reader with the impression that there is only one interpretation of the data reported here. It should thus be noted that the logic of the present investigation depends upon the assumption that the standard semantic context effect in lexical decision reflects, at least in part, preactivation of the target representation via the action of the prime (a prospective theory of priming; e.g., Collins \& Loftus, 1975; Neely, 1991; Neely \& Kahan, 2001). If this assumption is incorrect (i.e., if semantic priming [even for single words] reflects a completely retrospective process, then the presence of a semantic context effect in Experiment 1 can be understood without appealing to the idea of an activation block; see Forster, 1999, p. 6).

Returning to our preferred account, we note that the absence of a semantic context effect in the letter search task resembles what is seen when subjects search a prime display for a letter before making a lexical decision to a target. As discussed in the introduction, there is typically no semantic context effect in lexical decision following letter search of a prime, despite evidence of lexical involvement in the form of preserved morphemic priming and word-to-picture priming. These data have been taken to suggest that letter search on the prime blocks the action of feed-forward connections between lexical and semantic levels. The parallel between experiments in which there is letter search on the prime, and experiments in

Table 2

Repetition Priming: Mean Target Reaction Time (RTs, in Milliseconds) and Percentage Error (PE) in the Choice Task Procedure of Experiment 2

\begin{tabular}{|c|c|c|c|c|c|c|c|c|}
\hline \multirow{4}{*}{$\begin{array}{l}\text { Prime-Target } \\
\text { Relationship }\end{array}$} & \multicolumn{8}{|c|}{ Task } \\
\hline & \multicolumn{4}{|c|}{ Lexical Decision } & \multicolumn{4}{|c|}{ Letter Search } \\
\hline & \multicolumn{2}{|c|}{ Words } & \multicolumn{2}{|c|}{ Nonwords } & \multicolumn{2}{|c|}{ Words } & \multicolumn{2}{|c|}{ Nonwords } \\
\hline & RT & $\mathrm{PE}$ & RT & $\mathrm{PE}$ & RT & $\mathrm{PE}$ & RT & $\mathrm{PE}$ \\
\hline Unrelated & 1,088 & 2.4 & 1,206 & 4.6 & 1,586 & 5.4 & 1,650 & 6.0 \\
\hline Identical & 960 & 2.1 & 1,165 & 5.5 & 1,479 & 6.3 & 1,565 & 7.9 \\
\hline Difference $(\mathrm{U}-\mathrm{I})$ & 128 & 0.3 & 41 & -0.9 & 107 & -0.9 & 85 & -1.9 \\
\hline
\end{tabular}


which there is letter search on the target, suggests that there is also a between-level activation block in the latter case. That is, letter search on the target results in a between-level activation block that prevents the flow of activation from semantic level to lexical level. This block is experiment wide, but arises because some trials require letter search. Lexical decision yields a semantic context effect because the decision can be made by monitoring whether there is sufficient activation at the semantic level to indicate the presence of a word (e.g., Borowsky \& Besner, 1993; Stolz \& Neely, 1995). In contrast, letter search through a target is not affected by semantic relatedness because the influence of semantics does not extend down to the lexical level under these choice task conditions. Nonetheless, the lexical level is operative and facilitates performance in the letter search task, as seen in both Experiments 1 and $2 .{ }^{6}$ In short, regardless of whether subjects engage in letter search of the prime before processing a target or engage in letter search through a target following a prime, both kinds of experiments invoke between-level activation blocks, arguably so as to downplay the activation of irrelevant letters that would add to the processing load and disrupt performance. ${ }^{7}$

An implemented model of how activation spreads between levels has already been developed (McClelland \& Rumelhart, 1981). Implementing between-level activation blocks in order to demonstrate that all the relevant phenomena discussed here can be simulated within this framework is, in principle, a trivial problem, given that it can be accomplished by selectively zeroing out betweenlevel connections. Detailing the nature and workings of the control structure that oversees this and other processes will likely be more difficult to avoid in the future than it has been in the past.

\section{REFERENCES}

Allport, D. A., Styles, E. A., \& Hsien, S. (1994). Shifting intentional set: Exploring the dynamic control of tasks. In C. Umiltà \& M. Moscovitch (Eds.), Attention and performance XV: Conscious and nonconscious information processing (pp. 421-452). Cambridge, MA: MIT Press, Bradford Books.

Balota, D., \& ABrams, R. (1995). Mental chronometry: Beyond onset latencies in the lexical decision task. Journal of Experimental Psychology: Learning, Memory, \& Cognition, 21, 1289-1302.

Bauer, B., \& Besner, D. (1997). Processing in the Stroop task: Mental set as a determinant of performance. Canadian Journal of Experimental Psychology, 51, 61-68.

BECKER, C. A. (1979). Semantic context effects in visual word recognition. Journal of Experimental Psychology: Human Perception \& Performance, 5, 252-259.

Becker, C. A., \& Killion, T. H. (1977). Interaction of visual and cognitive effects in word recognition. Journal of Experimental Psychology: Human Perception \& Performance, 3, 389-401.

Besner, D., \& SMITH, M. C. (1992). Models of visual word recognition: When obscuring the stimulus yields a clearer view. Journal of Experimental Psychology: Learning, Memory, \& Cognition, 18, 468-482.

Besner, D., Smith, M. C., \& MacLeod, C. M. (1990). Visual word recognition: A dissociation of lexical and semantic processing. Journal of Experimental Psychology: Learning, Memory, \& Cognition, 16, 862-869.

Besner, D., \& Stolz, J. A. (1999). Unconsciously controlled process- ing: The Stroop effect reconsidered. Psychonomic Bulletin \& Review, 6, 449-455.

Besner, D., Stolz, J. A., \& Boutilier, C. (1997). The Stroop effect and the myth of automaticity. Psychonomic Bulletin \& Review, 4, 221-225.

Blum, T. L., \& Johnson, N. F. (1993). The effect of semantic priming on the detection of letters within words. Memory \& Cognition, 21, 389-396.

Borowsky, R, \& BESNER, D. (1993). Visual word recognition: A multistage activation model. Journal of Experimental Psychology: Learning, Memory, \& Cognition, 19, 815-840.

BuchanAn, L., \& BeSner, D. (1993). Reading aloud: Evidence for the use of a whole word nonsemantic pathway. Canadian Journal of Psychology, 47, 133-152.

Chiappe, P. R., Smith, M. C., \& Besner, D. (1996). Semantic priming in visual word recognition: Activation blocking and domains of processing. Psychonomic Bulletin \& Review, 3, 249-253.

Collins, A. M., \& LofTus, E. F. (1975). A spreading-activation theory of semantic processing. Psychological Review, 82, 407-428.

Forster, K. I. (1999). The microgenesis of priming effects in lexical access. Brain \& Language, 68, 5-15.

Friedrich, F. J., Henik, A., \& Tzelgov, J. (1991). Automatic processes in lexical access and spreading activation. Journal of Experimental Psychology: Human Perception \& Performance, 17, 792-806.

Henik, A., Friedrich, F. J., Tzelgov, J., \& Tramer, S. (1994). Capacity demands of automatic processes in semantic priming. Memory \& Cognition, 22, 157-168.

Herdman, C. M., Chernecki, D., \& Norris, D. (1999). Naming cAsE aLtErNaTeD words. Memory \& Cognition, 27, 254-266.

Johnston, J. C. (1981). Understanding word perception: Clues from studying the word superiority effect. In O. J. L. Tzeng \& H. Singer (Eds.), Perception of print: Reading research in experimental psychology (pp. 65-81). Hillsdale, NJ: Erlbaum.

Krueger, L. E., \& Weiss, M. E. (1976). Letter search through words and nonwords: The effect of fixed, absent, or mutilated targets. Memory \& Cognition, 4, 200-206.

Masson, M. E. J. (1991). A distributed memory model of context effects in word identification. In D. Besner \& G. Humphreys (Eds.), Basic processes in reading: Visual word recognition (pp. 233-263). Hillsdale, NJ: Erlbaum.

Masson, M. E. J. (1999). Semantic priming in a recurrent network: Comment on Dalrymple-Alford and Marmurek (1999). Journal of Experimental Psychology: Learning, Memory, \& Cognition, 25, 776-794.

McClelland, J. L. (1987). The case for interactionism in language processing. In M. Coltheart (Ed.), Attention and performance XII: The psychology of reading (pp. 3-35). Hillsdale, NJ: Erlbaum.

McClelland, J. L., \& Rumelhart, D. E. (1981). An interactiveactivation model of context effects in letter perception: Part 1. An account of basic findings. Psychological Review, 88, 375-407.

McRAe, K., \& BoIsvert, S. (1998). Automatic semantic similarity priming. Journal of Experimental Psychology: Learning, Memory, \& Cognition, 24, 558-572.

Meyer, D. E., Schvaneveldt, R. W., \& Ruddy, M. G. (1975). Loci of contextual effect on visual word recognition. In P. M. A. Rabbitt \& S. Dornic (Eds.), Attention and performance V (pp. 98-118). New York: Academic Press.

Morton, J. (1969). Interaction of information in word recognition. Psychological Review, 76, 165-178.

NeELY, J. H. (1991). Semantic priming effects in visual word recognition: A selective review of current findings and theories. In D. Besner \& G. Humphreys (Eds.), Basic processes in reading: Visual word recognition (pp. 264-336). Hillsdale, NJ: Erlbaum.

NeEly, J. H., \& KaHAN, T. (2001). Is semantic activation automatic? A critical reevaluation. In H. L. Roediger III, J. S. Nairne, I. Neath, \& A. M. Surprenant (Eds.), The nature of remembering: Essays in honor of Robert G. Crowder (pp. 69-93). Washington, DC: American Psychological Association.

Paap, K. R., Newsome, S. L., McDonald, J. E., \& Schvaneveldt, R. W. (1982). An activation-verification model for letter and word recognition. Psychological Review, 89, 573-594.

Plourde, C. E., \& Besner, D. (1997). On the locus of the word fre- 
quency effect in visual word recognition. Canadian Journal of Experimental Psychology, 51, 181-194.

Scarborough, D. L., Cortese, C., \& Scarborough, H. S. (1977). Frequency and repetition effects in lexical memory. Journal of Experimental Psychology: Human Perception \& Performance, 3, 1-17.

Smith, M. C., Meiran, N., \& Besner, D. (2000). On the interaction between linguistic and pictorial systems in the absence of semantic mediation: Evidence from a priming task. Memory \& Cognition, 28, 204-213.

Smith, M. C., Theodor, L., \& Franklin, P. E. (1983). The relationship between contextual facilitation and depth of processing. Journal of Experimental Psychology: Learning, Memory, \& Cognition, 9, 697-712.

STERnBerg, S. (1969). The discovery of processing stages: Extensions of Donders' methods. In W. G. Koster (Ed.), Attention and performance II (pp. 276-315). Amsterdam: North-Holland.

STERnberg, S. (1998). Discovering mental processing stages: The method of additive factors. In D. Scarborough \& S. Sternberg (Eds.), An invitation to cognitive science: Vol. 4. Methods, models, and conceptual issues (pp. 703-863). Cambridge, MA: MIT Press.

Stolz, J. A., \& BeSNER, D. (1996). Role of set in visual word recognition: Activation and activation blocking as nonautomatic processes. Journal of Experimental Psychology: Human Perception \& Performance, 22, 1166-1177.

Stolz, J. A., \& Besner, D. (1998). Levels of representation in visual word recognition: A dissociation between morphological and semantic processing. Journal of Experimental Psychology: Human Perception \& Performance, 24, 1642-1655.

Stolz, J. A., \& NeELY, J. (1995). When target degradation does and does not enhance semantic context effects in word recognition. Journal of Experimental Psychology: Learning, Memory, \& Cognition, 21, 596-611.

Stolz, J. A., Robidoux, S., \& Besner, D. (2001). Semantic context effects in visual word recognition: A simulation approach. Manuscript under revision.

TAFT, M. (1991). Reading and the mental lexicon. Hillsdale, NJ: Erlbaum.

Ziegler, J. C., Van Orden, G. C., \& Jacobs, A. M. (1997). Phonology can help or hurt the perception of print. Journal of Experimental Psychology: Human Perception \& Performance, 23, 845-860.

\section{NOTES}

1. Some theorists have concluded that the interactive activation (IA) framework cannot accommodate semantic priming because of the assumption that within-level connections are only inhibitory (e.g., Taft, 1991). In contrast, Stolz and Besner (1996) have discussed how an IA framework can produce semantic priming. Indeed, simulation work shows that there are a number of ways to produce semantic priming in the context of an IA framework (Stolz, Robidoux, \& Besner, 2001).

2 . The assumption of an activation block between the lexical and semantic levels is logically independent of the assumption that there is feedback from the lexical level to the letter level. Stolz and Besner $(1996,1998)$ assume feedback from the lexical level to the letter level because that work was cast in the context of the IA framework. Note, however, that other models of visual word recognition do not assume feedback from the lexical level to the letter level. For example, there are successful accounts of the word superiority effect (and by extension, the letter search task) that do not assume feedback between lexical and letter levels (e.g., Johnston, 1981; Paap et al., 1982).

3. One subject's data were discarded due to an excessive number of errors.

4. In order to investigate the possible effects of practice on activation blocking, 40 of the subjects in the experiment were tested in a second session. Although subjects were significantly faster both in letter search and lexical decision tasks on Day 2, the pattern did not change, in that the effect of practice did not enter into any significant interactions with priming.

5. RTs were considerably longer in this experiment, conducted at the University of Toronto, than in Experiment 1, conducted at the University of Waterloo. Reading skill may be responsible for this, given that the entrance requirements are higher at Waterloo than at the Scarborough Campus of the University of Toronto.

6. A new prediction is that degradation and semantic context will be additive rather than interacting factors in lexical decision under these conditions, given the argument that the typically observed interaction between these two factors in lexical decision depends on feedback from semantic to lexical levels (Borowsky \& Besner, 1993; Stolz \& Neely, 1995).

7. We emphasize, however, that an activation block is not always deployed. Stolz and Besner (1996, Experiment 1) demonstrated that letter search of the prime does not prevent a semantic context effect in lexical decision if the prime display precedes the to-be-searched letter by $200 \mathrm{msec}$. More importantly, the inclusion of this condition in the same block also affected trials on which the prime display and the letter to be searched for appeared simultaneously (Stolz \& Besner, 1996, Experiment 2). A semantic context effect was observed here too, despite the fact that it is exactly this latter condition in which a semantic context effect is typically eliminated when prime and target letter are presented simultaneously on all prime trials (Stolz \& Besner, 1996; Experiment 1). Activation blocks are clearly context dependent. It should also be noted that the general notion of an activation block (though not necessarily labeled as such), as a form of control has also been appealed to in a variety of other situations (see, e.g., Bauer \& Besner, 1997; Besner \& Stolz, 1999; Besner, Stolz, \& Boutilier, 1997; Borowsky \& Besner, 1993; Stolz $\&$ Neely, 1995). These blocks are likely unconscious in nature and controlled by a combination of task requirements and mental set.

(Manuscript received December 1, 1998; revision accepted for publication February 9, 2000.) 